\title{
MENTRANSFORMASIKAN SANG HEDONIS
}

\author{
Arsita $^{1)}$, Agustinus Sutanto $^{2)}$ \\ 1) Program Studi S1 Arsitektur, Fakultas Teknik, Universitas Tarumanagara, ansyla.arsita@gmail.com \\ 2) Program Studi S1 Arsitektur, Fakultas Teknik, Universitas Tarumanagara, afirawiniera@gmail.com
}

\begin{abstract}
Abstrak
Pariwisata dan Arsitektur bagi kota merupakan elemen penting yang sangat berpengaruh. Beda dengan area rural yang daya tariknya berasal dari alam, kota merupakan area yang didominasi oleh bangunan sehingga aktivitas di area kota tidak bisa lepas dari bangunan dan hal ini ditopang oleh arsitektur. Arsitektur dalam kota memiliki dua peran, hal ini dikemukakan oleh Jan Specht, yaitu Arsitektur Wisata dan Wisata Arsitektur. Membawa konsep Architourism ke dalam konteks Metropolis akan memberikan tantangan kepada penulis dalam menerapkan pendekatan Tourism Architecture. Untuk itu dalam merancang sebuah program wisata di area Metropolis, penulis akan berhadapan dengan kompleksitas karakter-karakter tersebut, guna menghasilkan program yang sesuai dengan kebutuhan masyarakat metropolis. Dengan ini penulis mengangkat isu mengenai paham duniawi, dimana paham duniawi ini memiliki tiga bagian yaitu Konsumerisme, Hedonisme, dan Sekuralisasi. Penulis mengangkat isu ini karena ingin menghadirkan sebuah wisata rohani ditengah kota jakarta yang penuh dengan orang-orang yang menganut paham duniawi. Proyek ini ditujukan dan diharapkan agar para penggunanya dapat sadar mengenai prihal paham duniawi, sehingga kehidupan mereka dapat menjadi lebih baik dan berarti
\end{abstract}

Kata kunci Wisata, Rohani, Konsumerisme, Hedonisme, Sekuralisasi

\begin{abstract}
Tourism and Architecture for cities are important elements that are very influential. Unlike the rural area whose appeal comes from nature, the city is an area dominated by buildings so that activities in the city area cannot be separated from buildings and this is supported by architecture. Architecture in the city has two roles, this was stated by Jan Specht, namely Architectural Tourism and Architectural Tourism. Bringing the concept of Architourism into the Metropolis context will pose a challenge to the author in applying the Tourism Architecture approach. For that, in designing a tourism program in the Metropolis area, the author will be faced with the complexity of these characters, in order to produce a program that fits the needs of the metropolis community. With this the author raises the issue of worldly understanding, where this worldly understanding has three parts, namely Consumerism, Hedonism, and Secularization. The author raises this issue because he wants to present a spiritual tour in the middle of the city of Jakarta that is full of people who embrace worldly understanding. This project is intended and expected so that its users can be aware of the worldly understanding, so that their lives can be better and more meaningful.
\end{abstract}

Keywords: Tourism, Spirituality, Consumerism, Hedonism, Secularization

\section{PENDAHULUAN}

Studio Perancangan Arsitektur 8 merupakan mata kuliah terakhir dari program studi sarjana arsitektur di Universitas Tarumanagara. Studio Desain menjadi basis utama dan dilakukan selama satu semester penuh. Focus untuk mata kuliah ini ditekankan pada proses dan cara berpikir untuk menyelesaikan permasalahan arsitektur serta menuangkannya dalam gambargambar arsitektural yang dapat dipertanggungjawabkan dan memenuhi standar professional. 


\section{KAJIAN LITERATUR}

Seperti yang sudah dikatakan oleh penulis, tema yang akan penulis kembangkan adalah Wisata Rohani, setelah mengupas tentang apa itu wisata dan apa itu rohani, penulis memutuskan untuk mengangkat permasalahan dari Paham Duniawi untuk dijadikan sebagai acuan dalam membuat proyek wisata rohani. Alasan penulis untuk mengangkat permasalahan ini dikarenakan penulis melihat pada jaman sekarang ini segala sesuatu yang berbau duniawi mulai dimaklumi dan semakin populer, walau sebelumnya hal tersebut merupakan suatu hal yang tabu atau tidak baik. Oleh karena itu penulis mencoba untuk mengupas permasalahan tersebut. Batasan dan ruang lingkup yang penulis lakukan berpusat pada kebiasaan masyarakat yang sangat mengejar kesenangan dengan berfoya-foya atau memamerkan hal yang mereka lakukan kepada publik.

Dengan adanya permasalahan seperti ini, penulis ingin menyediakan sebuah wadah dimana mereka (masyarakat) dapat mengenal apa itu paham duniawi dengan cara berwisata. Paham duniawi tidak dapat siembuhkan walau perlu disembuhkan, hal ini dikarenakan paham duniawi muncul karena salah satunya adalah perkembangan zaman. Teknologi, social media, dsb menjadi pemicu utama terjadinya paham duniawi.

Oleh karena itu, cara terbaik agar masyarakat (manusia) tidak terlalu terjerumus kedalam paham duniawi adalah dengan mengingatkan mereka kembali akan bahayanya paham duniawi dan jati diri mereka. Maka dari itu, kota metropolis perlu membuat suatu tempat dimana mereka dapat keluar dari paham duniawi dengan berwisata, sehingga mereka dapat mengolah diri mereka untuk ingat kembali apa tujuan mereka hidup yang sebenarnya.

Untuk itu penulis memikirkan solusi bagi para penganut paham duniawi dan solusi untuk para penganut paham duniawi adalah sebuah wadah yang bisa membantu mereka keluar sejenak dari paham duniawi mereka. Dimana didalamnya akan membuat mereka nyaman dan lupa akan keseharian mereka yang dituntut untuk melakukan banyak hal dan berfokus kepada kehidupan rohani mereka sendiri. Wadah ini harus mempunyai program yang baik agar para pelaku paham duniawi maupun orang awam dapat masuk dan dapat memahami tentang dunia paham duniawi itu sendiri, sehingga mereka diharapkan saat keluar dari wadah tersebut dapat tersadarkan akan apa yang sedang mewabah pada saat ini.

\section{METODE}

Untuk mendapatkan tapak bagi proyek ini, penulis membuat kuisioner dan membagikannya kepada 25 orang untuk mencari tempat yang paling banyak dikunjungi oleh mereka untuk melakukan kegiatan hedonisme. Dan setelah mendapatkan tapak disekitar tempat hedonis, penulis membuat sketsa abstrak untuk membentuk bangunan yang akan menjadi proyek tersebut.

\section{DISKUSI DAN HASIL}

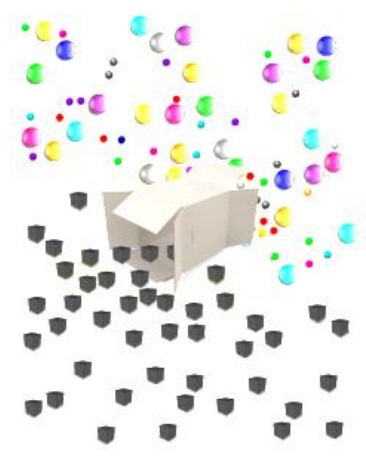

Gambar 1. Analogi Paham Duniawi 

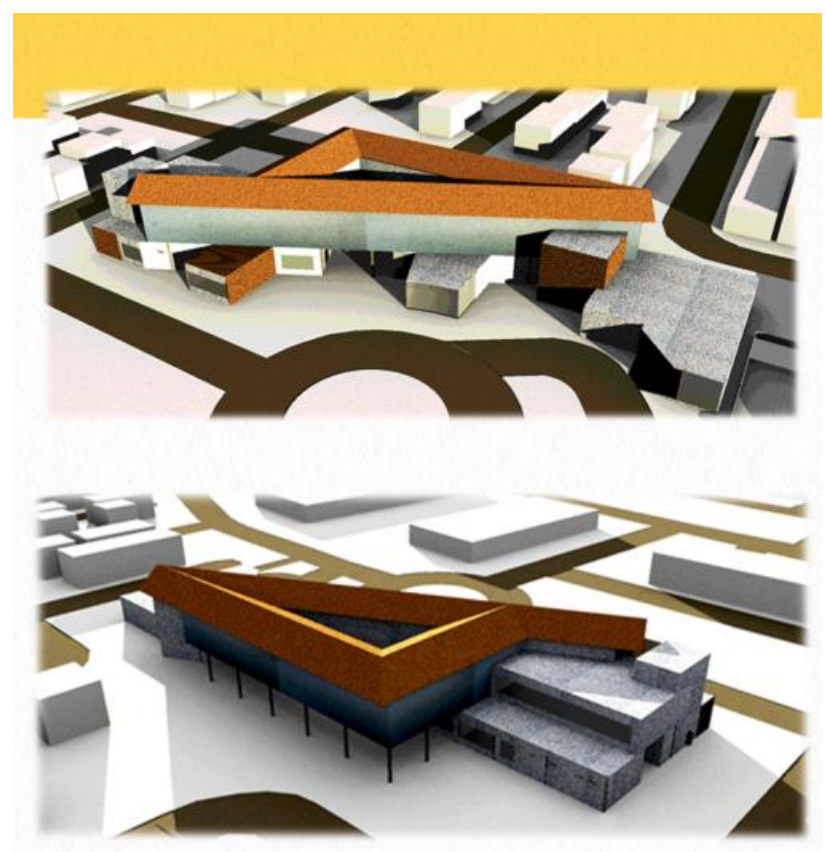

Gambar 2. Perspektif

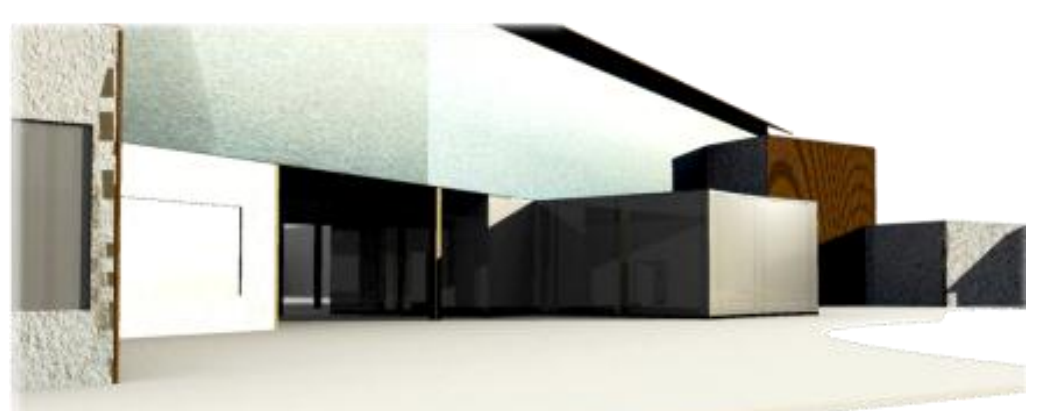

Gambar 3. Perspektif

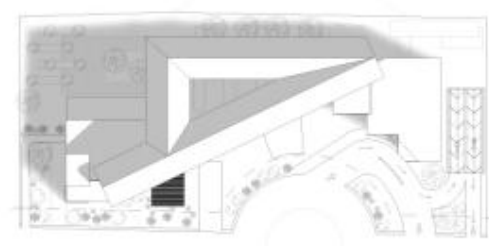

BLOK PLAN
SKALA : $: 509$

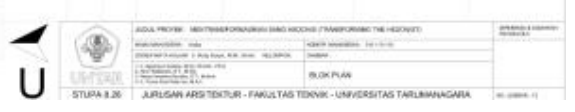

Gambar 4. Blok Plan 


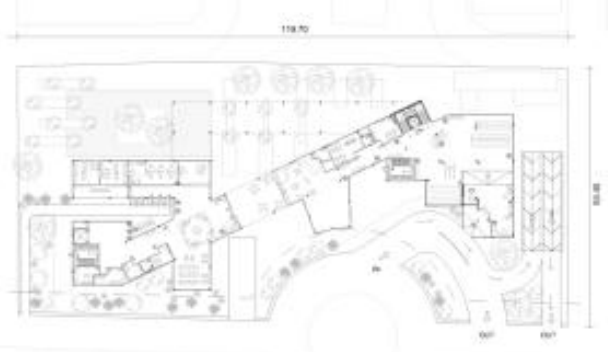

SITE PLAN

SKALA : 500

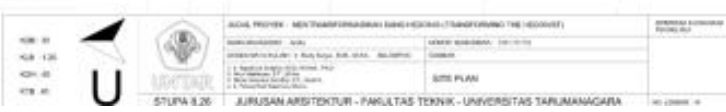

Gambar 5. Site Plan

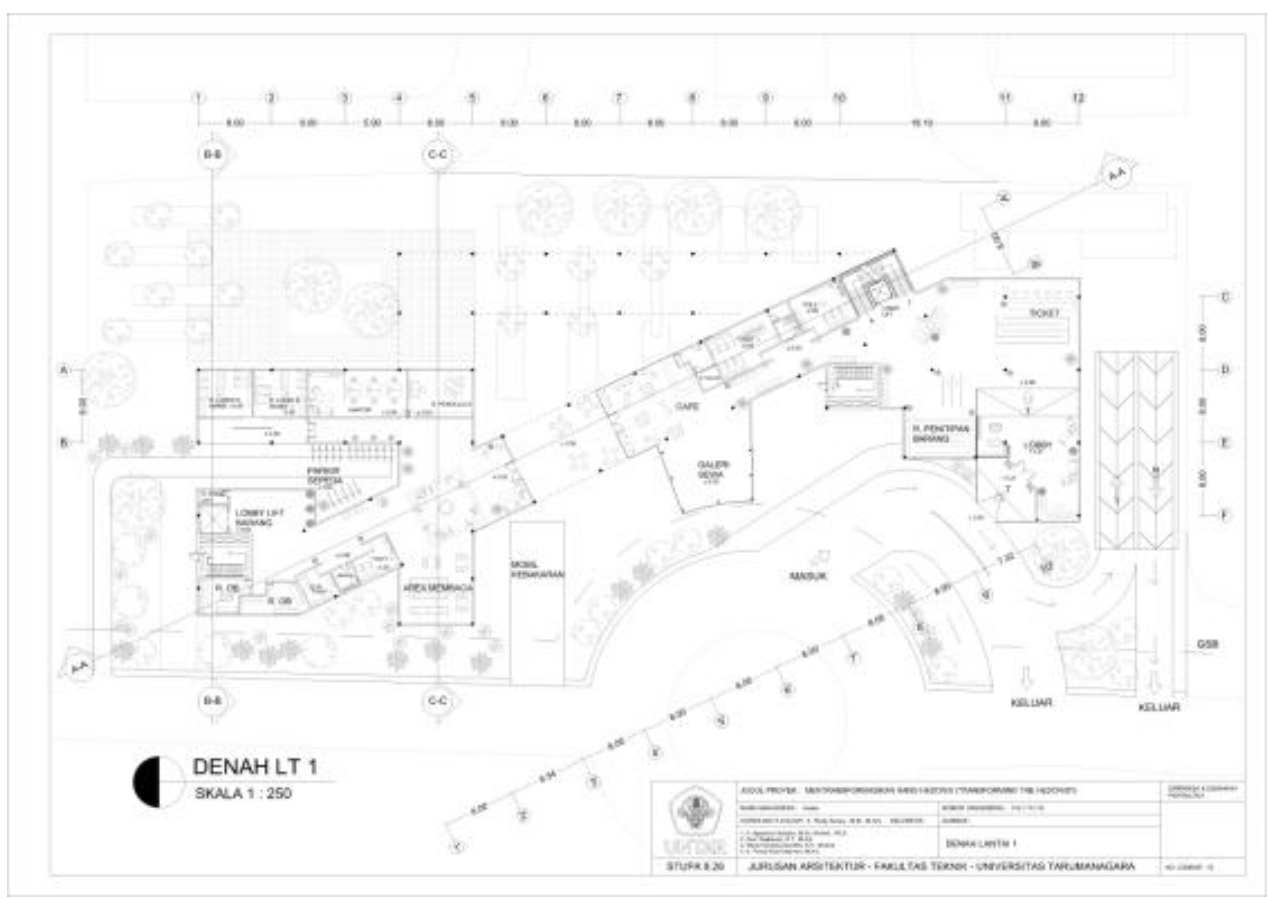

Gambar 6. Denah It 1 


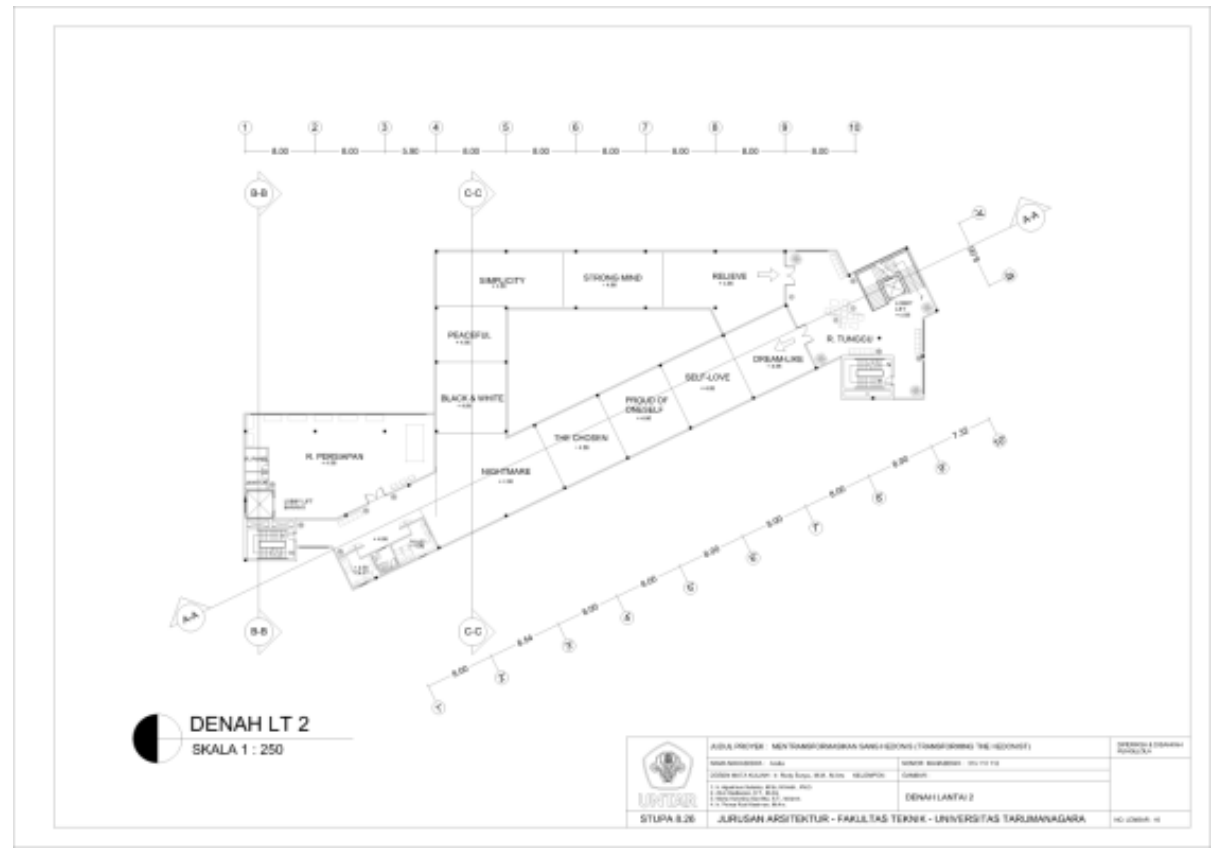

Gambar 7. Denah It 2

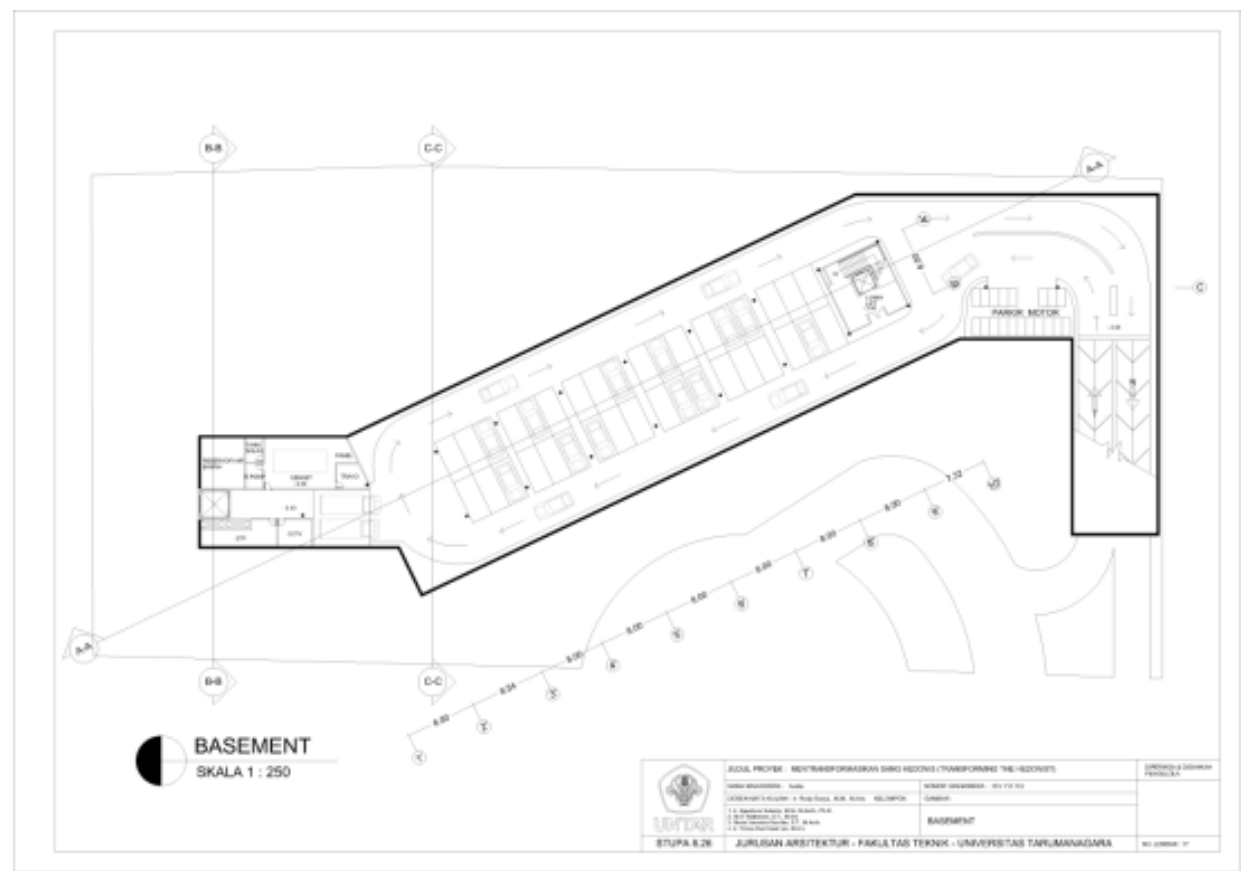

Gambar 8. Denah Basement 


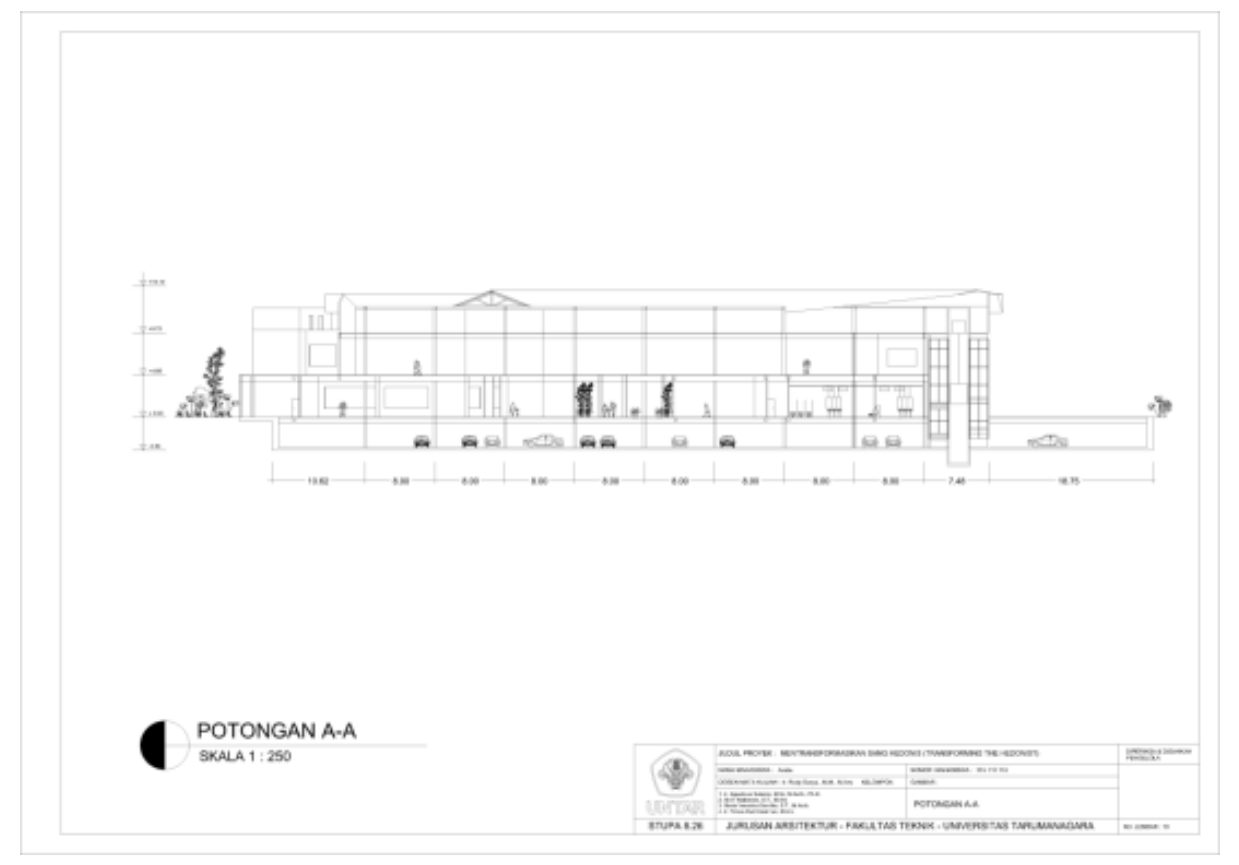

Gambar 9. Potongan A-A

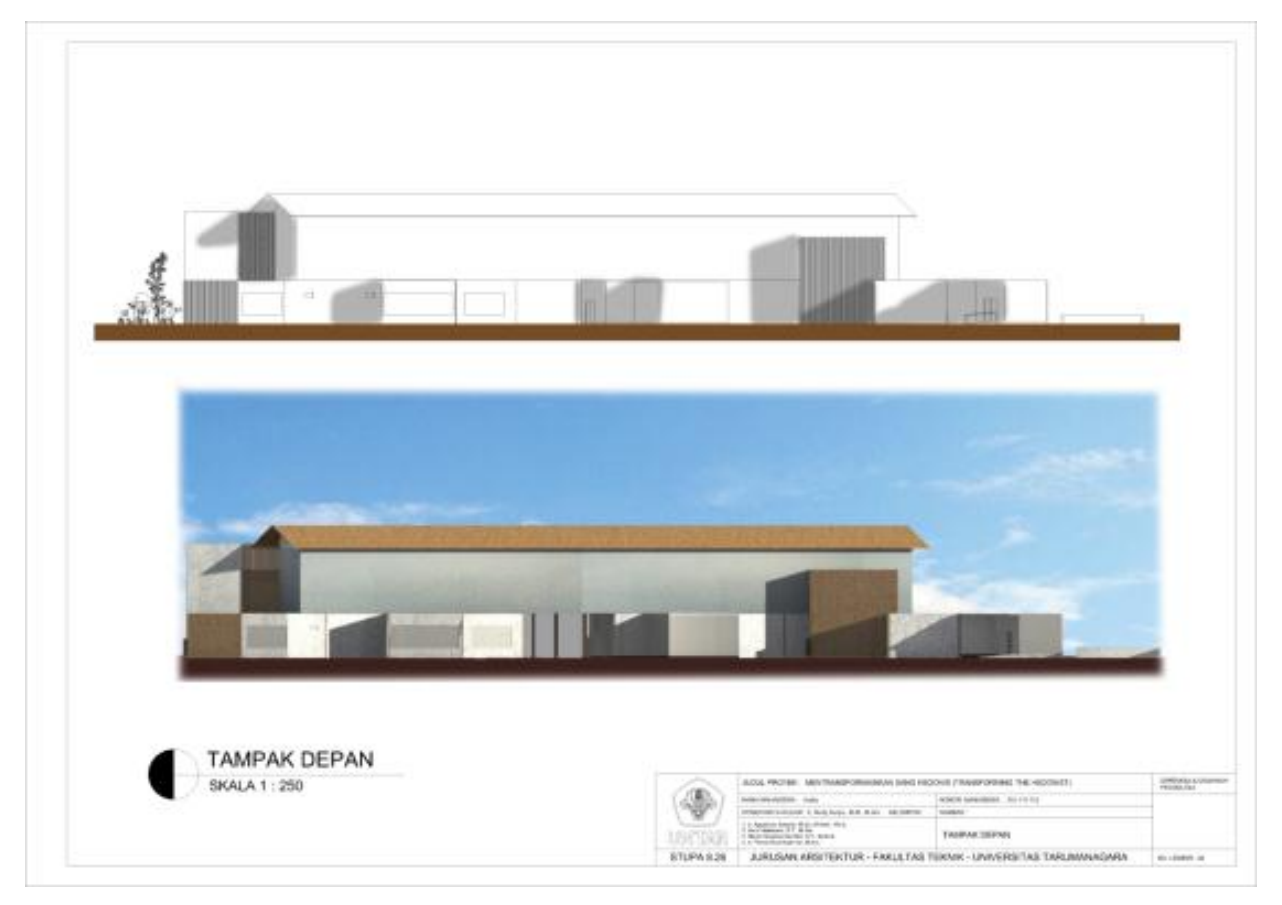

Gambar 10. Tampak Depan 


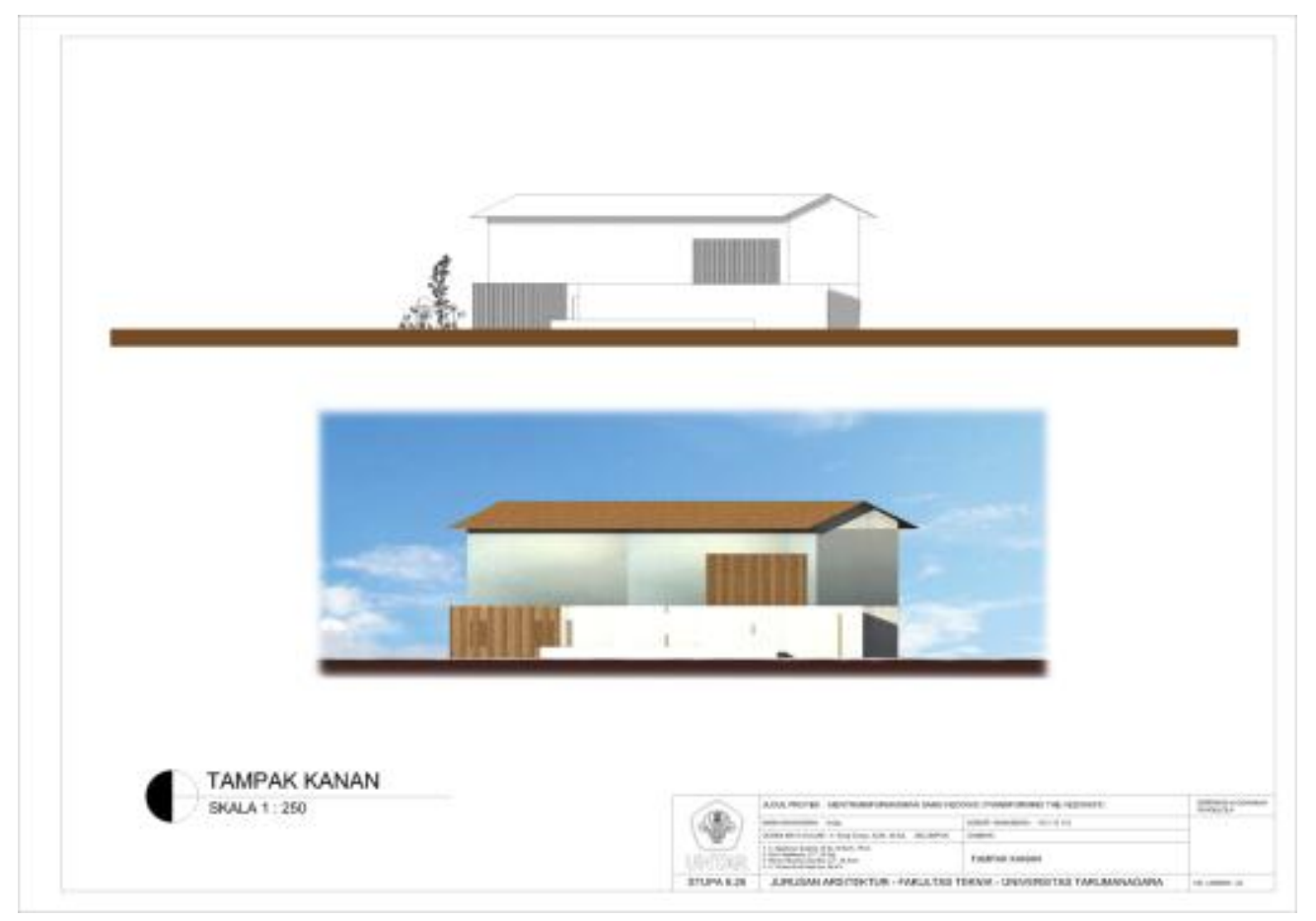

Gambar 11. Tampak Kanan

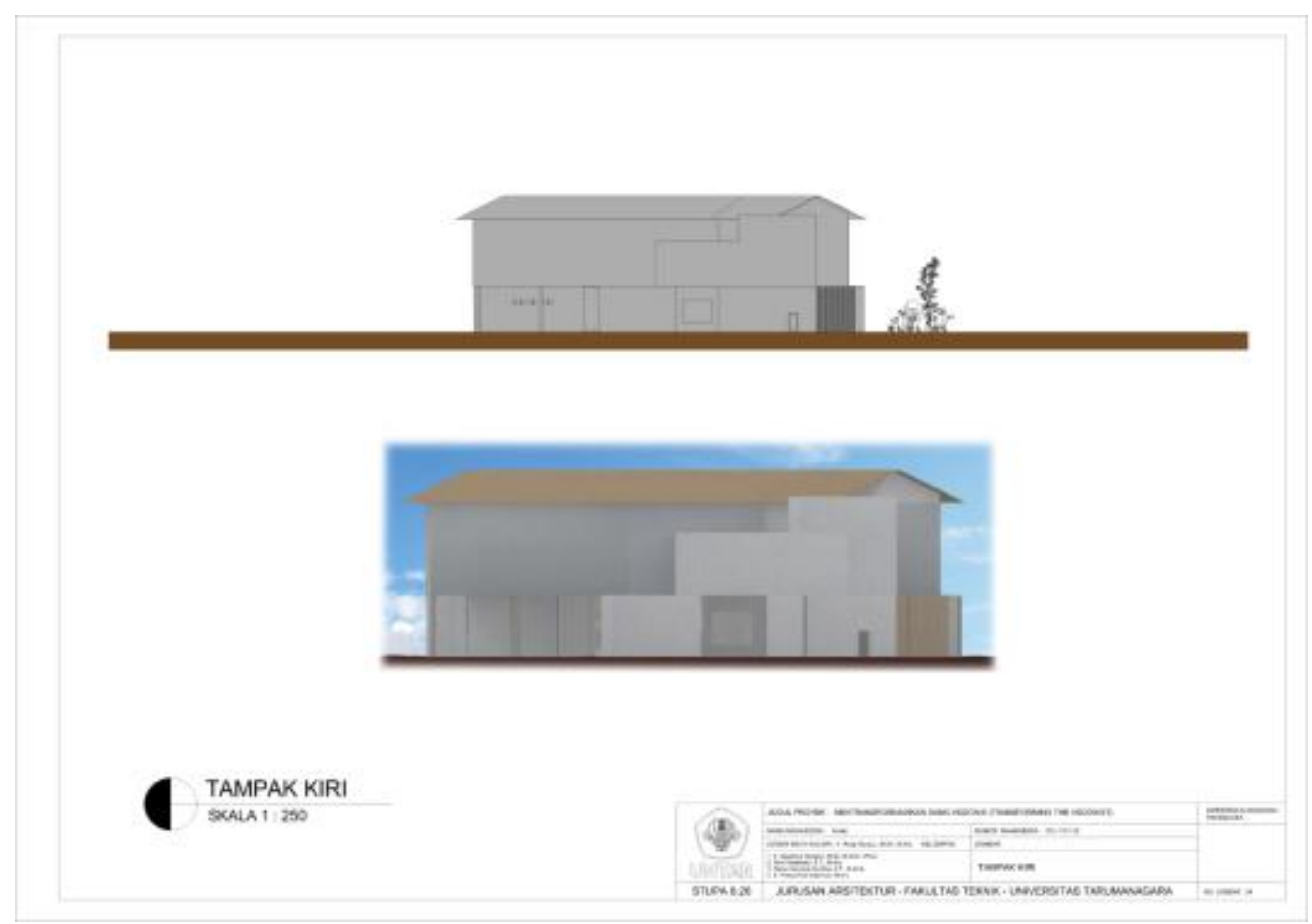

Gambar 12. Tampak Kiri 


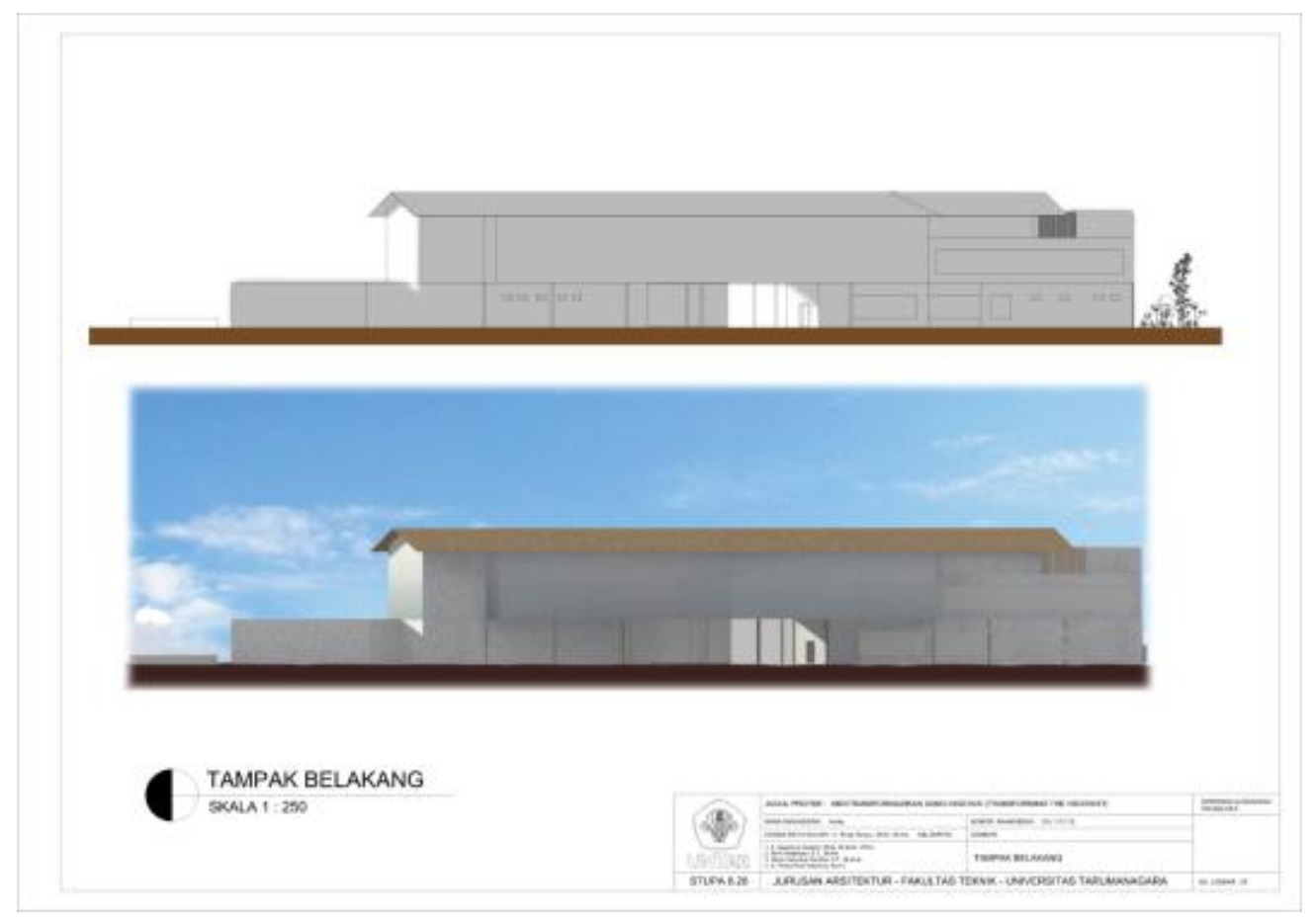

Gambar 13. Tampak Belakang

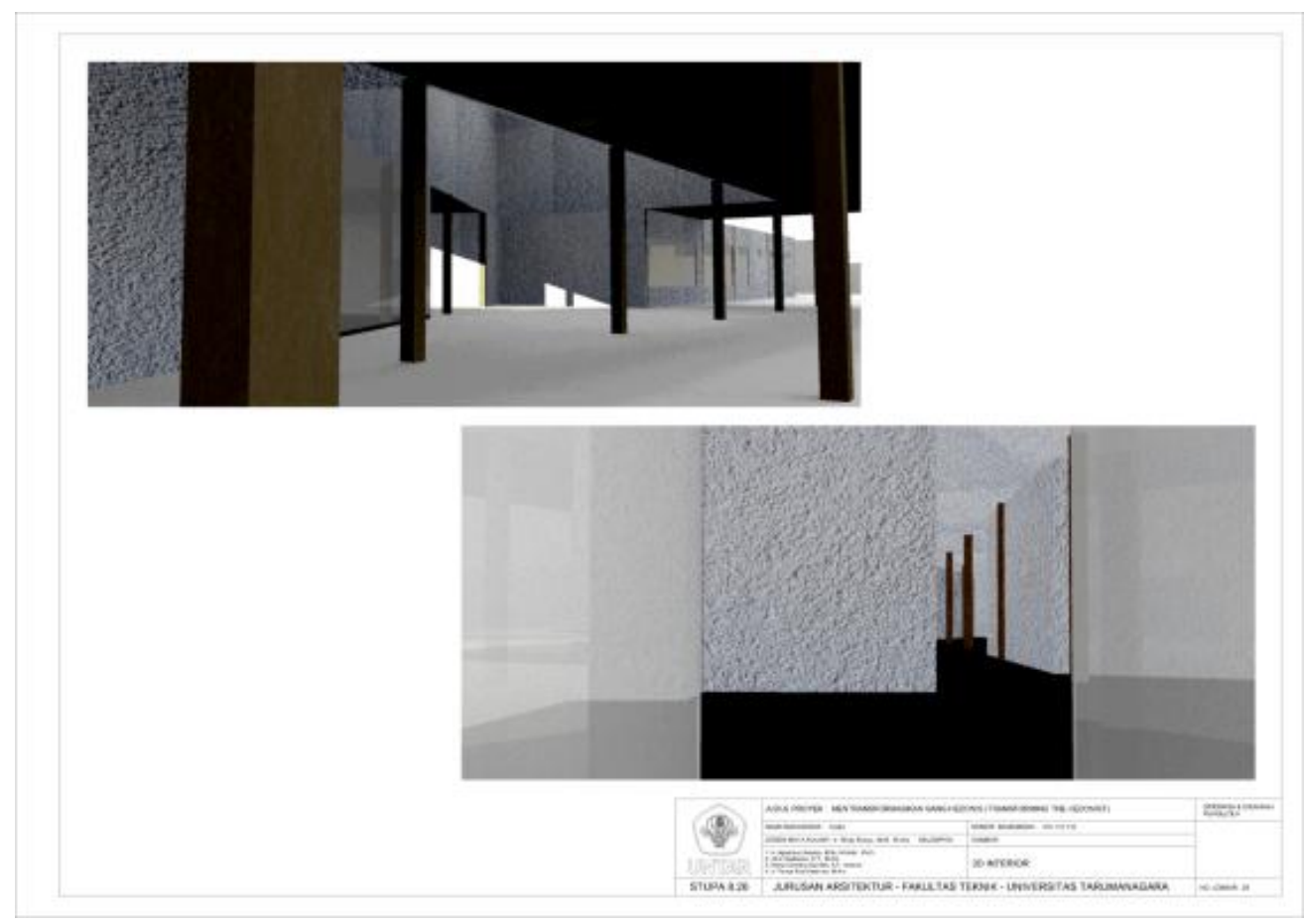

Gambar 14. Interior

\section{KESIMPULAN DAN SARAN}

Melihat issu yang terjadi dimasyarakat saat ini, penulis berfikir untuk membuat suatu wadah dimana penggunanya dapat mengerti makna yang ditujukan bagi mereka. Perancangan ini ditujukan agar masyarakat dapat hidup dengan lebih baik dan berkualitas, dengan membuat mereka mengerti betapa pentingnya kesehat jiwa bagi setiap individu. 


\section{UCAPAN TERIMA KASIH}

Penulis mengucapkan terimakasih kepada orang-orang yang telah menyemangati penulis untuk terus berusaha menyelesaikan proyek ini. Kepada keluarga yang terus menopang penulis hingga akhir perkuliahan, kepada teman-teman yang terus mendukung, dan kepada dosen-dosen yang terus membantu dan membimbing penulis, sehingga penulis dapat menyelesaikan pekerjaannya sebaik mungkin.

\section{REFERENSI}

Hasan, Rianto. Konsumerisme Dan Falsafah Hidup Masyarakat Indonesia. 10 Maret 2018. 11 Juli $2018<$ https://geotimes.co.id/opini/konsumerisme-pergeseran-falsafah-hidupmasyarakat-indonesia/>.

Makalah Tentang Paham Duniawi "HedonismeE". 17 Desember 2014. 11 Juli 2018 $<$ http://eraisna85.blogspot.com/2014/12/makalah-tentang-paham-duniawihedonisme.html>.

Merriam Webster. n.d. 10 Juli 2018 <https://www.merriam-webster.com/dictionary/spiritus>. Online Etymology Dictionary. n.d. 10 Juli 2018 <https://www.etymonline.com/word/spirit>.

Pengertian dari Konsumerisme. 2013. 11 Juli 2018 <http://www.wivrit.com/2013/12/pengertian-dari-konsumerisme.html>.

Pengertian Modernisasi, Sekularisasi Dan Westernisasi Serta Dampak Positifnya. 2016. 11 Juli 2018 <http://www.dosenpendidikan.com/pengertian-modernisasi-sekularisasi-danwesternisasi-serta-dampak-positifnya/>.

Pengertian Wisata Menurut Para Ahli. n.d. 10 Juli 2018 <https://www.scribd.com/doc/283979252/Pengertian-Wisata-Menurut-Para-Ahli>.

Sosiologi. 14 Januari 2014. 11 Juli 2018 <http://liamaliabetek.blogspot.com/2014/01/dampakperubahan-sosial.html>.

Specht, Jan. (2014). "Architectural Tourism ." Specht, Jan. Building for Urban Travel Destination. Springer Gabler.

The Origin Of The Spirit (Soul). n.d. 10 Juli 2018 <https://www.origin-of-religion.com/theorigin-of-spirit.html>.

Tornos: Origin of the word "tourism". n.d. 7 Juli 2018 <https://www.tornosnews.gr/en/others/13542-tornos-origin-of-the-word-tourism.html>.

Wisata : Pengertian, Ciri-ciri, Tujuan, Bentuk dan Unsurnya. 6 November 2013. 10 Juli 2018 <http://imamutasim.blogspot.com/2013/11/wisata-pengertian-ciri-ciri-tujuan-bent.html>. 